\title{
Association between Obesity and Impaired Glucose Tolerance in New Providence Adolescents as Demonstrated by the $\mathrm{HbA}_{1 \mathrm{c}}$ Test
}

\author{
K Rivers ${ }^{1}$, C Hanna-Mahase ${ }^{1}$, M Frankson ${ }^{2}$, F Smith ${ }^{3}$, S Peter ${ }^{3}$
}

\begin{abstract}
Objective: To explore the association between obesity and the development of impaired glucose tolerance (IGT) in Bahamian adolescents.

Methods: Eight hundred and seventy-three adolescents were randomly selected from five high schools in New Providence. Each student's weight, height, and waist and hip circumferences were recorded to determine body mass index (BMI). Individuals with BMIs above the $84^{\text {th }}$ and $95^{\text {th }}$ percentiles were classified as overweight and obese, respectively. Venous blood samples were collected from each subject and haemoglobin $A_{1 c}\left(H b A_{1 d}\right.$ ) levels were measured using a direct immunoassay method. The criterion established by the International Expert Committee for the diagnosis of IGT (HbA $A_{1 c}$ concentration of 6.0-6.4\%) was used. An analysis of covariance was performed to evaluate the relationship between obesity and IGT, and a logistic regression analysis predicted the risk of IGT based on BMI classification.

Results: Of the 861 adolescents who completed the study, 15.0\% were classified as overweight, $15.2 \%$ as obese and $7.9 \%$ as severely obese. The overall cumulative prevalence of IGT based on $\mathrm{Hb} A_{l c}$ levels was 16100 cases per 100000 adolescents and was greater in males than in females. Higher percentages of overweight and obese students were identified as having IGT compared with their normalweight counterparts. An analysis of covariance with post hoc analyses revealed that severely obese males and females, respectively were almost $26(O R=25.54,95 \%$ CI 9.92, 65.77) or 23 (OR $=22.96$, $95 \%$ CI 9.81, 53.73) times more likely to develop IGT than their normal-weight counterparts $(p<$ $0.005)$.
\end{abstract}

Conclusion: The data show a strong positive association between IGT and obesity among Bahamian adolescents.

Keywords: Body mass index, glycated haemoglobin $\left(\mathrm{HbA}_{1 \mathrm{c}}\right)$, impaired glucose tolerance, obesity, oral glucose tolerance test

\section{Asociación entre la Obesidad y los Trastornos de Tolerancia a la Glucosa entre los Adolescentes de Nueva Providencia Según lo Demostrado por la Prueba de $\mathrm{HbA}_{1 \mathrm{c}}$ \\ K Rivers ${ }^{1}$, C Hanna-Mahase ${ }^{1}$, M Frankson ${ }^{2}$, F Smith ${ }^{3}$, S Peter ${ }^{3}$}

\begin{abstract}
RESUMEN
Objetivo: Explorar la asociación entre la obesidad y el desarrollo de trastornos de tolerancia a la glucosa (IGT) en los adolescentes de Bahamas.

Métodos: Ochocientos setenta y tres adolescentes fueron seleccionados aleatoriamente de cinco escuelas secundarias en Nueva Providencia. Se registraron peso, altura, y las circunferencias de cintura y cadera de cada estudiante, para determinar el índice de masa corporal (IMC). Las personas con IMC por encima de los percentiles 84 y 95 fueron clasificados como con sobrepeso y obesos, respectivamente. Se obtuvieron muestras de sangre venosa de cada sujeto, y se midieron los niveles de hemoglobina $A_{l c}\left(H b A_{l d}\right)$ utilizando un método de inmunoensayo directo. Se utilizó el criterio
\end{abstract}

From: ${ }^{1}$ Department of Family Medicine, Princess Margaret Hospital, Public Hospitals Authority, Nassau, Bahamas, ${ }^{2}$ The University of the West Indies, School of Medicine and Clinical Research, Bahamas Open Campus and ${ }^{3}$ Department of Internal Medicine, Princess Margaret Hospital, Public Hospitals Authority, Nassau, Bahamas.
Correspondence: Dr K Rivers, 1 Liberty House, Clodien Avenue, Cardiff, Wales, CF14 3NS, United Kingdom. E-mail: leonriv@yahoo.com 
establecido por el Comité Internacional de expertos para el diagnóstico de IGT (concentración de $H b A_{l c}$ de 6.0-6.4\%). Se realizó un análisis de covarianza para evaluar la relación entre la obesidad y IGT, y un análisis de regresión logística para predecir el riesgo de IGT sobre la base de la clasificación del IMC.

Resultados: De los 861 adolescentes que completaron el estudio, 15.0\% fueron clasificados como con sobrepeso, $15.2 \%$ como obesos, y 7.9\% como extremadamente obesos. La prevalencia acumulativa general de IGT basada en los niveles de HbA Ic fue 16100 casos por 100000 adolescentes, y fue mayor en los varones que en las mujeres. Mayores porcentajes de estudiantes con sobrepeso y obesidad fueron identificados con IGT en comparación con sus contrapartes de peso normal. Un análisis de covarianza con análisis post-hoc reveló que los varones y hembras extremadamente obesos, respectivamente, fueron casi $26(O R=25.54,95 \%$ CI 9.92, 65.77) o $23(O R=22.96,95 \%$ CI 9.81, 53.73) veces más propensas a desarrollar IGT que sus contrapartes de peso normal $(p<0.05)$.

Conclusión: Los datos muestran una fuerte asociación positiva entre IGT y obesidad entre los adolescentes de las Bahamas.

Palabras claves: Índice de masa corporal, la hemoglobina glucosilada $\left(\mathrm{HbA}_{1 \mathrm{c}}\right)$, trastornos de tolerancia a la glucosa, obesidad, prueba oral de tolerancia a la glucosa

West Indian Med J 2013; 62 (8): 706

\section{INTRODUCTION}

As with many cultures, trends in diet and lifestyle within the Bahamian culture can significantly influence the overall health of its people. Available nutrition and food consumption data indicate that, for the past 30 to 40 years, the typical Bahamian diet has consisted of a growing percentage of starches, fats and sodium, and a decreased amount of fruits and vegetables (1). These changes, along with an increasingly sedentary lifestyle, may be responsible for higher rates of obesity in The Bahamas, leading to an increased incidence of diseases, such as Type 2 diabetes and hypertension. Historically, these diseases have affected adults, but they now appear to be rising steadily in both children and adolescents. The 2001 Bahamas Living Conditions Survey (2) noted that $65 \%$ of adult Bahamians are overweight, and $23 \%$ of Bahamians between 11 and 20 years of age are either overweight or obese. This staggering statistic prompted this research project, the aim of which was to conduct the first local study to explore the association between obesity and the development of impaired glucose tolerance (IGT) among adolescents in The Bahamas. Impaired glucose tolerance is a pre-diabetic condition characterized by elevated blood glucose levels.

Obesity can lead to a number of cardio-metabolic diseases, including dyslipidaemia, hypertension, insulin resistance, IGT and Type 2 diabetes. The results of numerous studies have supported the claim that obesity is positively associated with the development of abnormal glucose metabolism $(3,4)$. Because the diabetes disease process begins long before the onset of overt Type 2 diabetes (5), this study targeted adolescents who are more likely to present with the earlier phases of the disorder (ie insulin resistance or IGT). Adolescents across various body mass index (BMI) categories were included in this investigation.

The BMI classifications for children and adolescents are age- and gender-specific (6). According to the 1995
World Health Organization's (WHO) Expert Committee on Physical Status (7), a normal-weight individual is defined as having a BMI between the $5^{\text {th }}$ and $84^{\text {th }}$ percentiles, and an obese individual is defined as having a BMI between the $95^{\text {th }}$ and $98^{\text {th }}$ percentiles. This study explored potential trends in the development of IGT across these different BMI categories.

Traditionally, the fasting glucose and two-hour postprandial glucose tests were the only methods used to diagnose IGT; however, both the American Diabetes Association (ADA) and an International Expert Committee (IEC) have established criteria for the determination of IGT based on the haemoglobin $\mathrm{A}_{1 \mathrm{c}}\left(\mathrm{HbA}_{1 \mathrm{c}}\right)$ test $(8,9)$. Haemoglobin $\mathrm{A}_{1 \mathrm{c}}$ is formed when haemoglobin is glycated as a result of its exposure to plasma glucose, and its concentration can be measured to ascertain blood glucose levels. The ADA considers an $\mathrm{HbA}_{1 \mathrm{c}}$ concentration of 5.7-6.4\% to be indicative of IGT; according to the IEC, the range is $6.0-6.4 \%$. The present study used the IEC's more conservative range to classify adolescents with IGT. The use of the $\mathrm{HbA}_{1 \mathrm{c}}$ test for the diagnosis of IGT is advantageous, because it not only reflects the acute glycaemia that has traditionally been measured by plasma glucose testing, but also chronic hyperglycaemic states. In addition, patients do not have to fast or restrict their diets prior to testing.

The main goals of this project were to determine the prevalence of IGT among a sample of 13- to 19-year-old individuals in New Providence (the capital island of The Bahamas) and evaluate its association with obesity. We also aimed to assess and compare glucose tolerance in adolescents of different BMI subcategories. These objectives were intended to address the current knowledge gap that exists regarding these impairments in Bahamian adolescents. We hypothesize that adolescents who are obese are more likely to develop IGT compared to those who are normal. 


\section{SUBJECTS AND METHODS}

This cross-sectional study involved obese and non-obese adolescents aged 13 to 19 years from five different public high schools on the island of New Providence. The study spanned January to March of 2012. Permission to recruit study participants was reviewed and granted by the Ministry of Education, the Ministry of Health National Ethics Committee, and the combined Ethics Committee of The University of the West Indies and the Public Hospitals Authority. Study volunteers were required to sign a letter of assent and present a letter of consent signed by a parent or guardian. In addition, each volunteer was asked for verbal consent prior to testing and advised that he/she could withdraw from the study at any time. Preliminary evaluations indicated that none of the students was known to have diabetes, thyroid disease, or any other disorders that could potentially interfere with glucose metabolism. None of the students was taking medications that could affect plasma glucose levels and none reported the recent use of marijuana or alcohol.

A multistage sampling procedure was employed in which the schools and classes were selected first via simple random sampling. Volunteers were chosen using a stratified sampling method to ensure that a sufficient number of students was selected from each BMI category. Students were asked to complete a questionnaire, exploring behaviours associated with being either overweight or obese. Demographic questions (eg age, gender, ethnicity, family history of diabetes and socio-economic status) were also included in the survey.

Each volunteer's weight, height, and waist and hip circumferences were measured according to the WHO STEPwise approach to surveillance (STEPS) manual (10). Weight was recorded to the nearest $0.1 \mathrm{~kg}$ for barefooted volunteers, using a standard electronic scale; height was measured to the nearest $0.1 \mathrm{~cm}$, using a freestanding stadiometer. Waist and hip circumferences were measured to the nearest $0.1 \mathrm{~cm}$ using a tape measure. A venous blood sample was collected from each student and placed in an ethylenediamine tetraacetic acid tube. The $\mathrm{HbA}_{1 \mathrm{c}}$ immunoassay was performed on the blood samples using the Dimension RXL chemistry analyser (Siemens AG).

Descriptive and inferential analyses were performed to address each facet of the hypothesis and objectives. Con- tinuous variables were summarized using the mean and standard deviation, and categorical variables were summarized using a frequency table (count and percentages). The significance of univariate differences was assessed using the Student's $t$-test for continuous variables and the Chi-square test for categorical variables. The effect size was assessed by calculating Cohen's $d$ with respect to continuous variables, $\varphi$ for $2 \times 2$ Chi-squared tests for independence, and Cramer's V when there was more than one degree of freedom for the Chisquared test.

Mean $\mathrm{HbA}_{1 \mathrm{c}}$ levels were compared among different BMI categories using analysis of covariance (ANCOVA) with adjustments for potential covariates. If the main effect of ANCOVA was significant, a post hoc test for pairwise comparisons among groups with Bonferroni adjustment was conducted. The association between IGT (outcome variable) and obesity predictor (BMI) was tested using logistic regression with adjustment of possible covariates. Odds ratios and $95 \%$ confidence intervals were calculated. All tests of significance were two-tailed, and an alpha $(\alpha)$ was set at 0.05 . The analyses were performed using IBM SPSS Statistics v. 19.0 (IBM SPSS, IBM Corporation, Armonk, NY, USA).

\section{RESULTS}

Of the 873 students who initially volunteered to participate, 861 completed the study. Ninety-eight per cent of the students were Black, and the remaining $2 \%$ were Caucasian, Hispanic, or Asian. The prevalence of IGT is presented in Table 1. The $\mathrm{HbA}_{1 \mathrm{c}}$ tests showed that $82.6 \%$ of the students were normal (no IGT), 16.1\% had IGT and 1.3\% were diabetic. A comparison of $\mathrm{HbA}_{1 \mathrm{c}}$ test results between male and female students revealed a significant difference, $\chi^{2}(1, \mathrm{n}$ $=861)=8.75, p=0.013 ; 19.9 \%$ of males had IGT but none had diabetes, whereas $14.4 \%$ of females had IGT and $1.9 \%$ had diabetes.

The prevalence of IGT in relation to BMI category is shown in Table 2. Based on $\mathrm{HbA}_{1 \mathrm{c}}$ concentrations, $17.8 \%$ of overweight and $6.2 \%$ of normal-weight adolescents had IGT. Impaired glucose tolerance was much more common among obese $(35.1 \%)$ and severely obese adolescents $(55.9 \%)$. A one-way ANCOVA was conducted with $\mathrm{HbA}_{1 \mathrm{c}}$ levels as the dependent variable, BMI category as the independent variable, and age as the covariate. The results were significant

Table 1: Summary of fasting glucose, two hour post-load glucose and haemoglobin ( $\mathrm{Hb}) \mathrm{A}_{1 \mathrm{c}}$

\begin{tabular}{|c|c|c|c|c|c|}
\hline Variable & $\begin{array}{l}\text { Total population } \\
\quad(\mathrm{n}=861)\end{array}$ & $\begin{array}{l}\text { Male students } \\
\quad(\mathrm{n}=\mathbf{2 7 2})\end{array}$ & $\begin{array}{l}\text { Female students } \\
\quad(\mathrm{n}=\mathbf{5 8 9})\end{array}$ & $p$-value ${ }^{\dagger}$ & $\begin{array}{r}\text { Effect } \\
\text { size }^{\dagger \dagger}\end{array}$ \\
\hline Mean $\mathrm{HbA}_{1 \mathrm{c}}$ value $(\%)$ & $5.6 \pm 0.41$ & $5.58 \pm 0.42$ & $5.61 \pm 0.4$ & 0.821 & -0.073 \\
\hline $\begin{array}{l}\text { Assessment based on } \mathrm{HbA}_{1 \mathrm{c}} \\
\text { Normal } \\
\text { IGT } \\
\text { Diabetes }\end{array}$ & $\begin{array}{c}711(82.6) \\
139(16.1) \\
11(1.3)\end{array}$ & $\begin{array}{c}218(80.1) \\
54(19.9) \\
0(0.0)\end{array}$ & $\begin{array}{c}493(83.7) \\
85(14.4) \\
11(1.9)\end{array}$ & $0.013^{*}$ & 0.101 \\
\hline
\end{tabular}

Note. †Two-sided independent $t$-test (continuous variables) or Chi-squared test (categorical variable) to determine the association between gender and each variable; *indicates significance at 0.05 level. 
Table 2: Prevalence of impaired glucose tolerance (IGT) by body mass index (BMI) categories

\begin{tabular}{|c|c|c|c|c|c|c|c|c|c|}
\hline \multirow[b]{2}{*}{ BMI status } & \multicolumn{3}{|c|}{ Total population $(n=861)$} & \multicolumn{3}{|c|}{ Male students $(n=272)$} & \multicolumn{3}{|c|}{ Female students $(n=589)$} \\
\hline & Normal & IGT & Diabetes & Normal & IGT & Diabetes & Normal & IGT & Diabetes \\
\hline \multicolumn{10}{|c|}{ IGT based on $\mathrm{HbA}_{1 \mathrm{c}}$} \\
\hline Underweight & $19(100.0)$ & $0(0.0)$ & $0(0.0)$ & $3(100.0)$ & $0(0.0)$ & $0(0.0)$ & $16(100.0)$ & $0(0.0)$ & $0(0.0)$ \\
\hline Normal & 481 (93.6) & $32(6.2)$ & $1(0.2)$ & $166(92.7)$ & $13(7.3)$ & $0(0.0)$ & $315(94.0)$ & $19(5.7)$ & $1(0.3)$ \\
\hline Overweight & $106(82.2)$ & $23(17.8)$ & $0(0.0)$ & $25(75.8)$ & $8(24.2)$ & $0(0.0)$ & $81(84.4)$ & 15 (15.6) & $0(0.0)$ \\
\hline Obese & $82(62.6)$ & $46(35.1)$ & $3(2.3)$ & $14(51.9)$ & $13(48.1)$ & $0(0.0)$ & $68(65.4)$ & $33(31.7)$ & $3(2.9)$ \\
\hline Severely obese & $23(33.8)$ & $38(55.9)$ & $7(10.3)$ & $10(33.3)$ & $20(66.7)$ & $0(0.0)$ & $13(34.2)$ & $18(47.4)$ & $7(18.4)$ \\
\hline
\end{tabular}

for both males $[\mathrm{F}(4,266)=12.89, p<0.001]$ and females $[\mathrm{F}(4,583)=26.82, p<0.001]$ (Table 3$)$. A percentage of the total variance in $\mathrm{HbA}_{1 \mathrm{c}}$ levels $(17.2 \%$ for males and $15.9 \%$ for females) was accounted for by the five BMI categories (controlling for the effect of age). Post hoc tests revealed significantly higher $\mathrm{HbA}_{1 \mathrm{c}}$ levels in obese and severely obese adolescents compared with normal-weight adolescents, regardless of gender. In addition, severely obese males had significantly higher $\mathrm{HbA}_{1 \mathrm{c}}$ levels than overweight males, and obese and severely obese females had significantly higher $\mathrm{HbA}_{1 \mathrm{c}}$ levels than overweight females.

A logistic regression was performed to evaluate the association between IGT and obesity. Potential covariates such as age and ethnicity were not included in the model, since they were not statistically significant. The results shown in Table 4 demonstrated that, compared with normalweight males, overweight males were about four times (OR $=4.09)$, obese males were nearly 12 times $(\mathrm{OR}=11.86)$, and

Table 3: Pairwise comparisons of haemoglobin $(\mathrm{Hb}) \mathrm{A}_{1 \mathrm{c}}$ levels by body mass index (BMI) status

\begin{tabular}{|c|c|c|c|c|c|c|c|}
\hline & \multirow{2}{*}{ Mean } & \multirow{2}{*}{$\begin{array}{c}\text { Adjusted } \\
\text { mean }\end{array}$} & \multicolumn{3}{|c|}{ Adjusted mean differences } & \multirow[b]{2}{*}{ Obese } & \multirow{2}{*}{$\begin{array}{c}\text { Severely } \\
\text { obese }\end{array}$} \\
\hline & & & Underweight & Normal & Overweight & & \\
\hline \multicolumn{8}{|l|}{ Males $^{a}$} \\
\hline Underweight & 5.433 & 5.462 & - & & & & \\
\hline Normal & 5.487 & 5.489 & -0.027 & - & & & \\
\hline Overweight & 5.570 & 5.558 & -0.096 & -0.069 & - & & \\
\hline Obese & 5.837 & 5.830 & -0.368 & $-0.341^{*}$ & -0.272 & - & \\
\hline Severely obese & 5.960 & 5.963 & -0.502 & $-0.474^{*}$ & $-0.405^{*}$ & -0.134 & - \\
\hline \multicolumn{8}{|l|}{ Females $^{b}$} \\
\hline Underweight & 5.525 & 5.529 & - & & & & \\
\hline Normal & 5.514 & 5.515 & 0.015 & - & & & \\
\hline Overweight & 5.581 & 5.582 & -0.052 & -0.067 & - & & \\
\hline Obese & 5.773 & 5.770 & -0.241 & $-0.256^{*}$ & $-0.189^{*}$ & - & \\
\hline Severely obese & 6.089 & 6.089 & $-0.560^{*}$ & $-0.575^{*}$ & $-0.508^{*}$ & $-0.319^{*}$ & - \\
\hline
\end{tabular}

${ }^{*}$ significant at 0.05 level, ${ }^{\mathrm{a}}: \mathrm{R}^{2}=0.172,{ }^{\mathrm{b}}: \mathrm{R}^{2}=0.159$

Table 4: Logistic regression models of impaired glucose tolerance (IGT)

\begin{tabular}{lrrrrr}
\hline & B & SE & Wald & \multicolumn{1}{c}{$\boldsymbol{p}$} & OR (95\% CI) \\
\hline Male, $\mathbf{n = 2 6 9}{ }^{a}$ & & & & & \\
IGT (HbA ${ }_{1 c}$ ) & & & & & \\
Intercept & -2.547 & 0.288 & 78.211 & $<0.001$ & \\
Overweight & 1.408 & 0.498 & 7.991 & 0.005 & $4.09(1.54,10.84)$ \\
Obese & 2.473 & 0.481 & 26.439 & $<0.001$ & $11.86(4.62,30.43)$ \\
Severely obese & 3.240 & 0.483 & 45.069 & $<0.001$ & $25.54(9.92,65.77)$ \\
& & & & & \\
Female, $\mathbf{n}=\mathbf{5 6 2}^{b}$ & & & & & \\
IGT (HbA $\left.{ }_{1 c}\right)$ & & & & & \\
Intercept & -2.808 & 0.236 & 141.304 & $<0.001$ & \\
Overweight & 1.122 & 0.367 & 9.333 & 0.002 & $3.07(1.49,6.31)$ \\
Obese & 2.085 & 0.318 & 43.126 & $<0.001$ & $8.05(4.32,14.99)$ \\
Severely obese & 3.134 & 0.434 & 52.151 & $<0.001$ & $22.96(9.81,53.73)$ \\
\hline
\end{tabular}

a: Nagelkerke $R^{2}=0.336,{ }^{b}$ : Nagelkerke $R^{2}=0.228$ 
severely obese males were more than 25 times $(\mathrm{OR}=25.54)$ more likely to have IGT. Results for females showed that, compared to normal-weight females, overweight females were three times $(\mathrm{OR}=3.07)$, obese females were eight times $(\mathrm{OR}=8.05)$, and severely obese females were nearly 23 times $(\mathrm{OR}=22.96)$ more likely to have IGT.

\section{DISCUSSION}

Consistent with trends seen in many other developed nations, adolescent obesity and the associated metabolic derangement, IGT (4), are on the rise in The Bahamas. The present study revealed that the overall cumulative prevalence of IGT among New Providence adolescents between 13 and 19 years of age is 16000 per 100000 individuals. In particular, the percentage of adolescents with IGT was highest among the obese $(35.1 \%)$ and severely obese $(55.9 \%)$. Bhargava et al (11) noted a similar relationship between IGT and BMI in adolescents. Additionally, similar to findings reported by Charles et al (12), 6.2\% of normal-weight subjects were also found to have IGT (Table 2).

Based on these data, it is clear that adolescents with normal BMIs are less likely to suffer from IGT, whereas those with increased BMIs are at a higher risk for developing this disorder. Further study is needed to ascertain whether this risk is present in younger obese children (ie children younger than 13 years of age), as there are currently no data available for younger age groups in The Bahamas. In addition, there are many questions to be explored. For example, what potential benefits (if any) exist for the overall national health budget if early intervention programmes are developed to reduce the frequency of IGT in youths who are obese but have normal glycaemic indices? More importantly, for adolescents with IGT, what types of therapy could prevent further beta cell damage and progression to overt Type 2 diabetes (and at what age should therapy be initiated)? The high prevalence of obesity and IGT among adolescents represents an added burden on our healthcare system, which is already burdened by overt Type 2 diabetes. In fact, in 2002, there were 165 lower leg amputations solely due to diabetes (13). Our data support the view of the IEC that tests such as the $\mathrm{HbA}_{1 \mathrm{c}}$ screen can be used to detect pre-diabetic states in at-risk children and adolescents before the onset of classical symptoms (8). The $\mathrm{HbA}_{1 \mathrm{c}}$ test in this study has been standardized for precision and accuracy according to the National Glycohaemoglobin Standardization Program (14) using a direct immunoassay method. This protocol eliminates the confusion and difficulty in interpretation of $\mathrm{HbA}_{1 \mathrm{c}}$ values that can result from multiple testing methods. The $\mathrm{HbA}_{1 \mathrm{c}}$ results in our study, measured by direct immunoassay, are consistent with those published in the Diabetes Control and Complications Trial, which relied on high-performance liquid chromatography to measure $\mathrm{HbA}_{1 \mathrm{c}}$ levels (15).
Along with the rise in childhood obesity in The Bahamas, the number of cases of Type 2 diabetes in children and adolescents is also expected to increase. As such, the need for early screening to identify at-risk youths is paramount to diabetes prevention. Weis et al (16) reported that, unlike adults, youths with IGT progress very quickly to Type 2 diabetes. Additionally, young people with Type 2 diabetes develop co-morbidities at a more rapid rate compared to youths without diabetes (17). Although obesity is the most significant contributor to the development of insulin resistance and IGT in adolescence $(4,18)$, there is evidence that the effects of hormones, such as growth hormone and insulinlike growth factor 1, may also temporarily contribute to this condition during puberty $(19,20)$. This may partially explain the increased prevalence of IGT in the tested subjects.

Our data showed that severely obese males and females were almost respectively, 26 and 23 times more likely to have IGT than normal-weight subjects. Based on this compelling evidence, there is a need for a coordinated effort by all stakeholders to develop national action plans to combat obesity and prevent the development of IGT and Type 2 diabetes. As there is currently no cure for diabetes, improved methods for monitoring glycaemic indices for early detection of dysglycaemia, such as the $\mathrm{HbA}_{1 \mathrm{c}}$ test, can allow for early treatment and have the potential to improve the lives of adolescents at risk for this disorder.

The present study has several strengths. The crosssectional study design allowed for quick and inexpensive implementation, which precluded the need for follow-up or inclusion of previous medical records. In addition, the sample size was large, which afforded increased precision and a good representative population. The study questionnaire controlled for covariates that may have confounded the results. Finally, to the best of our knowledge, this is the first local study to evaluate IGT prevalence in obese and nonobese adolescents in The Bahamas.

This study also had some limitations. Complete blood counts and haemoglobin electrophoresis were not performed to determine whether participants had anaemia or any type of haemoglobinopathy, which are known to interfere with accurate $\mathrm{HbA}_{1 \mathrm{c}}$ measurement. Hyperlipidaemia can also affect $\mathrm{HbA}_{1 \mathrm{c}}$ levels, but no lipid studies were performed on the subjects. Finally, no kidney or liver function tests were performed, despite evidence that renal and hepatic impairment can lead to inaccurate $\mathrm{HbA}_{1 \mathrm{c}}$ values (21).

In conclusion, the data reveal a strong positive association between IGT and obesity among New Providence adolescents, confirming the original hypothesis that obese adolescents are more likely to develop IGT compared to normal-weight adolescents. Obesity in young people is clearly a serious public health issue in The Bahamas. Establishing programmes to reduce obesity rates may enable us to prevent the progression from IGT to Type 2 diabetes in this at-risk group. 


\section{ACKNOWLEDGEMENTS}

Heartfelt thanks to The Bahamas Ministry of Education and PS Mrs Elma Garraway as well as the superintendants, principals, teachers, guidance counsellors, staff and students of RM Bailey, CV Bethel, CI Gibson, CC Sweeting and the Government High School; members of the research team, and the Princess Margaret Hospital Chemistry Laboratory Department. Deepest gratitude to the sponsors, including the Public Hospitals Authority, Sir Durward Knowles, Mr Harald McPike, Cable Bahamas Cares Foundation, Atty Craig Butler, the Golden Gates Clinic, Colina General Insurance Agency Ltd, Galleria Cinemas Ltd, Aetos Holdings Ltd, and Restaurant Bahamas Ltd. Special thanks to Dr Hui Liu for additional statistical advice.

\section{REFERENCES}

1. Food and Agriculture Organization of the United Nations. Nutrition country profile for The Bahamas; 2003 [cited 2012 Mar 26]. Available from ftp://ftp.fao.org/ag/agn/nutrition/ncp/bhs.pdf

2. Government of The Bahamas, Department of Statistics. Bahamas Living Conditions Survey, 2001. Nassau, Bahamas: Department of Statistics; 2004.

3. Saaristo T, Barengo N, Korpi-Hyövälti E, Oksa H, Puolijoki H, Saltevo $\mathrm{J}$ et al. High prevalence of obesity, central obesity and abnormal glucose tolerance in the middle-aged Finnish population. BMC Public Health 2008; 29: 423

4. Sinha R, Fisch G, Teague B, Tamborlane WV, Banyas B, Savoye M et al. Prevalence of impaired glucose tolerance among children and adolescents with marked obesity. N Engl J Med 2002; 346: 802-10.

5. Færch K, Vaag A, Holst J, Hansen T, Jørgensen T, Borch-Johnsen K. Natural history of insulin sensitivity and insulin secretion in the progression from normal glucose tolerance to impaired fasting glycemia and impaired glucose tolerance: The Inter99 Study. Diabetes Care 2009; 32: 439-44.

6. Must A, Anderson SE. Body mass index in children and adolescents: considerations for population-based applications. Int J Obes Relat Metab Disord 2006; 30: 590-4.

7. World Health Organization. Physical status: the use \& interpretation of anthropometry. Geneva: World Health Organization Tech Rep Ser; 1995: 854
8. International Expert Committee. International Expert Committee report on the role of the $\mathrm{A}_{1 \mathrm{c}}$ assay in the diagnosis of diabetes. Diabetes Care 2009; 32: 1327-34.

9. American Diabetes Association Position Statement: standards of medical care in diabetes - 2010. Diabetes Care 2010; 33 (Suppl 1): 1161.

10. World Health Organization. WHO STEPS surveillance manual: the WHO STEPwise approach to chronic disease risk factor surveillance. Geneva: World Health Organization; 2005.

11. Bhargava SK, Sachdev HS, Fall CHD, Osmond C, Lakshmy R, Barker DJP et al. Relation of serial changes in childhood body-mass index to impaired glucose tolerance in young adulthood. N Engl J Med 2004; 350: $865-75$.

12. Charles MA, Pettitt DJ, Saad MF, Nelson RG, Bennett PH, Knowler WC. Development of impaired glucose tolerance with or without weight gain. Diabetes Care 1993; 16: 593-6.

13. Jones W. Diabetes - chronic and costly! [Editorial]. The Bahama Journal 2012; 15: 2.

14. Little RR, Rohlfing CL, Sacks DB. National Glycohemoglobin Standardization Program (NGSP) Steering Committee. Status of hemoglobin $\mathrm{A}_{1 \mathrm{c}}$ measurement and goals for improvement: from chaos to order for improving diabetes care. Clin Chem 2011; 57: 205-14.

15. Hanas $\mathrm{R}$, John $\mathrm{G}$, on behalf of the International $\mathrm{HBA}_{1 \mathrm{c}}$ Consensus Committee. 2010 consensus statement on the worldwide standardization of the hemoglobin A1C measurement. Diabetes Care 2010; 33: 1903-4.

16. Weiss R, Taksali SE, Tamborlane W, Burgert T, Savoye M, Caprio S. Predictors of changes in glucose tolerance status in obese youths. Diabetes Care 2005; 28: 902-9.

17. Flint A, Arslanian S. Treatment of Type 2 diabetes in youth. Diabetes Care 2011; 34 (Suppl 2): 177-83.

18. Kahn S, Hull R, Utzschneider K. Mechanisms linking obesity to insulin resistance and type 2 diabetes. Nature 2006; 444: 840-6.

19. Moran A, Jacobs DR Jr, Steinberger J, Cohen P, Hong CP, Prineas R et al. Association between the insulin resistance of puberty and the insulin-like growth factor-I/growth hormone axis. J Clin Endocrinol Metab 2002; 87: 4817-20.

20. Bloch CA, Clemons PSMA. Puberty decreases insulin sensitivity. J Pediatr 1987; 110: 481-7.

21. Mostafa SA, Daview MJ, Srinivasan B, Carey ME, Webb D, Khunti K. Should glycated haemoglobin $\left(\mathrm{HbA}_{1 \mathrm{c}}\right)$ be used to detect people with type 2 diabetes mellitus and impaired glucose regulation? Postgrad Med J 2010; 86: 656-62. 